\title{
O Espaço da Biodiversidade: uma leitura teológica da criação na perspectiva da sustentabilidade ambiental
}

\author{
Lúcio Flávio Ribeiro Cirne
}

\section{Introdução}

Pensar a criação em perspectiva ecológica é uma tarefa que pode ser caracterizada por apresentar, ao mesmo tempo, complexidade e pertinência. Talvez daí resulte o seu caráter atrativo e desafiador. Por ser uma temática bastante complexa e abrangente, pode ser analisada sob diferentes óticas e, por isso, pede uma delimitação na abordagem. Por sua pertinência e atualidade, aponta para dimensões que afetam concretamente a vida humana e o bem-estar geral do nosso planeta. Conjugando esses dois fatores, buscamos, no presente artigo, uma delimitação temática bastante atual, isto é, abordaremos o tema na perspectiva da biodiversidade, uma vez que estamos no Ano Internacional da Biodiversidade. Partindo do pressuposto de que a crise ecológica é uma crise socioambiental, atingindo igualmente os seres humanos e o seu entorno natural, o nosso argumento é que o caminho para a sustentabilidade passa pelo respeito e valorização da pluralidade e da diferença. Num primeiro momento, veremos como uma leitura trinitária da criação fundamenta a biodiversidade. Em seguida, apresentaremos o espaço geográfico como mediação para uma leitura social do ambiente. No terceiro e último momento, veremos como essa categoria geográfica se aproxima da questão da sustentabilidade segundo o viés da sociobiodiversidade. 


\section{A Trindade como fundamentação teológica da biodiversidade}

Na perspectiva da nossa fé, tudo que existe foi criado por Deus através da sua comunicação "para fora" de si, possibilitada pela própria autocomunicação divina que já acontece no interior da Trindade. A criação, portanto, é um dom pessoal e livre de Deus para participar de sua comunhão trinitária, isto é, participação na comunhão de vida do Filho com o Pai através do Espírito $^{1}$. A Trindade é uma comunidade de Pessoas distintas, interrelacionadas, em comunhão de ser, de bem e de vida, de modo que o universo inteiro e cada criatura têm sua origem nessa amorosa comunhão trinitária. Nas palavras de Catherine LaCugna, "toda a realidade, já que procede de Deus, é pessoal e relacional" ${ }^{2}$. Ou seja, a criação, que tem a sua origem neste fecundo amor trinitário, é também intrínseca e vitalmente relacional.

Conceber a Trindade como Pessoas dinamicamente interrelacionadas e em comunhão entre si significa estar em sintonia com o pensamento ecológico que, priorizando a dimensão sistêmica ou relacional, vê todos os seres como membros de uma comunidade biótica, interligados por uma cadeia de conexões vitais.

Através da Sabedoria de Deus todas as coisas foram feitas e o universo inteiro se mantém. Estando junto do Criador, ela participa do processo criativo e da conservação do mundo. É o encanto do próprio Deus, maravilhando-se com o mundo criado e sentindo alegria pelas criaturas humanas (Pr 8,22-31). Ela alcança o universo de um extremo ao outro e governa retamente todas as coisas ( $\mathrm{Sb} \mathrm{8,1).} \mathrm{Na} \mathrm{plenitude} \mathrm{dos} \mathrm{tempos,} \mathrm{fez} \mathrm{morada} \mathrm{entre}$ nós (Pr 9,1; Jo 1,14). Em Jesus de Nazaré, a Sabedoria que está no coração do universo se revela na história e nos mostra a face do Deus Criador a quem invoca como seu Pai e, através desse relacionamento filial, dá completo sentido à sua existência. Jesus Cristo é a Sabedoria divina por quem todas as coisas foram criadas $(\mathrm{Cl} \mathrm{1,16;} \mathrm{Hb} \mathrm{1,2} \mathrm{Jo,} \mathrm{1,3).} \mathrm{Ressuscitado,} \mathrm{torna-se} \mathrm{a} \mathrm{pro-}$ messa e o início da Nova Criação. Nele todas as coisas são redimidas, reconciliadas e transformadas ( $\mathrm{Rm} \mathrm{8,21;} \mathrm{Cl} 1,20$; Ef 1,20). Cada criatura, em Jesus Cristo, participa da finalidade criacional e salvífica do Criador. A figura bíblica da Sabedoria, portanto, é central para uma teologia cristã da criação e para uma compreensão ecológica da Trindade. Jesus, "por quem tudo

\footnotetext{
1 JUNGES, J. R. Ecologia e Criação. Resposta cristã à crise ambienal. S. Paulo: Edições Loyola, 2001, p. 36.

${ }^{2}$ LACUGNA, C. M. God for Us: The Trinity and Christian Life. San Francisco: HarperSanFrancisco, 1991, p. 248.
} 
existe e por quem nós somos" (1Cor 8,5), é a Sabedoria divina da qual surge a oikos, a morada de todas as criaturas ${ }^{3}$.

Jesus - Sabedoria encarnada - também é o Verbo, o Filho eterno, distinto do Pai. Em Jesus de Nazaré, cuja existência humana revela uma relação peculiar com Deus, encontra-se uma perfeita convergência de um duplo movimento, isto é, o relacionamento do homem Jesus diante de Deus reflete o relacionamento do Filho eterno no interior da comunhão Trinitária. Isto significa que o ser humano Jesus de Nazaré, sendo distinto do Pai, revela que a eterna relação entre a primeira e a segunda pessoa da Trindade pode sair do seio trinitário e, através do Verbo que conserva a condição divina, passa à existência humana como criatura. A criação, assim, teria um "espaço" na própria Trindade, isto é, no Filho, pois "a criação como o 'totalmente outro' de Deus pode ter seu 'lugar' somente no Filho" 4 .

A criação do ser humano e de todas as demais criaturas - criadas em total liberdade por Deus - têm sua possibilidade nesta autodiferenciação entre o Pai o Filho, cujo ponto culminante é a Encarnação. A multiforme pluralidade do mundo e a alteridade de cada ser vivo se fundamentam, assim, a partir da autocomunicação amorosa de Deus que tem o seu Outro eterno, ou seja, as pessoas da Trindade ${ }^{5}$. Dito de outro modo, a criação, em sua diversidade plural, é dada pela distinção do Verbo na Trindade - o Filho eterno que, pela ação do Espírito, se abre à existência humana em Jesus de Nazaré. Por ser criada em Cristo e em vista de Cristo, a criação recebe a diversidade de suas formas.

A distinção do Filho na Trindade nos leva a pensar que a criação foi feita sobre o modelo do Verbo e, sendo assim, ela se torna como que a morada do Verbo. Numa perspectiva ecológica, aqui nos deparamos com um ponto de especial interesse. Por ser a morada do Lógos divino, encontramos assim, como acertadamente propõe A. Gesché, uma motivação propriamente teologal para cuidar e preservar - "salvaguardar" - a terra em que habitamos ${ }^{6}$.

Quatro indicativos, segundo Gesché, nos levam a ver o nosso mundo perpassado pelo Lógos, tornando-se a morada do Verbo antes mesmo da criação: a) desde antes da fundação do mundo (S1 77,12), o Logos (a Sabedoria de Deus) já se achava "na superfície da terra" (Pr 8,30-31); b) durante a criação: o mundo foi feito pela palavra criadora divina, e o Pai criou o

\footnotetext{
${ }^{3}$ EDWARDS, D. Jesus, The Wisdom of God. An ecological theology. N. York: Orbis Books, 1995, p. 33 e 119-120.

${ }^{4}$ GRESHAKE, Gilbert. Citado por NOEMI, Juan. Mysterium Creationis: Sobre a Possibilidade de uma Aproximação à Realidade como Criação de Deus. In: SUSIN, L. C. (org.) Mysterium Creationis: um olhar interdisciplinar sobre o universo. São Paulo: Paulinas, 1999, p. 224.

${ }^{5}$ Ibid.

${ }^{6}$ GESCHÉ, A., O Cosmo, S. Paulo: Paulinas, 2004, p. 76-106.
} 
mundo segundo o Exemplar que o Verbo era para ele; c) na Encarnação "o Verbo se fez carne e habitou entre nós" (Jo 1,14); e d) a terra é morada do Verbo a título de Parusia. A terra é até o fim (realização escatológica) lugar de Deus, morada onde o seu Lógos vai julgar o mundo $(1$ Cor 15,24$)$ e para onde "ele virá em sua glória"7.

Sendo, pois, morada do Lógos, nossa terra é portadora de "estruturas de capacidade" que nela foram colocadas pelo princípio criador de Deus. A terra não é um mecanismo rigidamente determinado, desencantado e sem vida. Ao contrário, ela está cheia de criatividade, de virtualidades; é viva e fonte de vida, pois o Lógos que a preenche não é apenas Sabedoria e Luz, mas também Vida (Jo 1,4). Por causa da força do Lógos que o habita, o nosso mundo tem uma destinação de eternidade, uma capacidade de transfiguração a partir das novas possibilidades cuja origem se encontra na palavra criadora divina e cujo delineamento último manifestar-se-á quando o Lógos da Parusia vier em sua glória ${ }^{8}$.

Como toda a criação, o nosso mundo é transpassado pelo Logos do criador. Ele é um kosmos logikós, criado com uma racionalidade, um sentido, dotado de capacidades, em estado de capacidade ${ }^{9}$. Por conseguinte, podemos dizer que Ele tem a sua logicidade própria, pois ele existe por Deus, por sua palavra criadora. E, em relação a nós, seres humanos, ele tem uma anterioridade, "não precisa de nós para existir" - lembra Gesché, advertindonos contra um arrogante antropocentrismo que vê no cosmos um simples alicerce antrópico.

Embora o homem, o único criado à imagem e seme-
lhança do Verbo, seja um logikon infinitamente superior
ao cosmo, ele não é uma exceção absoluta nesse reino
do Logos. O cosmo tem o seu logos, que lhe é próprio:
talvez logos kosmikos... Pelo fato de ter sido criado in
principio (em todos os sentidos do termo), foi-lhe dado
ser desde sempre fundado e permanecer, para além da
queda, na grandeza de suas inaugurações ${ }^{10}$.

É daí que surge a motivação propriamente teologal - ainda que as outras razões sejam perfeitamente justificadas e legítimas - para o cuidado ecológico da terra, pois ela é a morada do Lógos. O ser humano - portador da imagem do Verbo e, por isso, único em sua capacidade dialógica - é o ser

\footnotetext{
${ }^{7}$ Ibid., p. 77-78.

${ }^{8}$ Ibid., p. $94-95$.

${ }^{9}$ Ibid., p. 155.

${ }^{10}$ Ibid., p. 156.
} 
responsável que pode responder positivamente ao apelo de Deus, assumir o cuidado da Terra e, assim, garantir, respeitar e completar essa morada do Verbo de Deus. Enfim, por ser morada do Lógos, essa nossa Terra deve ser preservada como Terra de destinação - mais do que uma destinação ecológica ou moral - uma terra de salvação que foi doada ao ser humano. Nas palavras de Gesché:

\begin{abstract}
[A Igreja] também deve estar no mundo por diferença. E tal diferença é, principalmente, anunciar esta terra como uma terra de destinação teologal, como obra de salvação divina, como uma promessa de eternidade. Ordenando esta terra certamente como morada do homem, mas também como oikoumene do Logos ${ }^{11}$.
\end{abstract}

Nessa visão trinitária da criação, também é importante observar que o relacionamento de Jesus com o Pai, ao revelar o amor do Pai para com o Filho, mostra também que o motivo da criação é a participação na comunhão divina, pois todas as criaturas nos céus e na terra são reunidas em Cristo, através do Espírito, para participar da vida divina (Ef 1,10). O Verbo não só é o princípio da distinção e alteridade para todas as criaturas, mas também o elo que liga toda a criação entre si e com o Criador ${ }^{12}$. É no amor para com o Filho que o Pai revela o seu amor por todas as demais criaturas. O sentido da criação e a identidade de toda a criatura, portanto, se manifestam na humanidade de Jesus, isto é, "reconhecer Deus como Deus, honrá-lo como Pai e Criador" $" 13$.

Toda a existência de Jesus aponta para a Origem sem origem, a fonte de toda plenitude - fontalis plenitudo - de onde provém a Vida e a Bondade ${ }^{14}$. Essa fonte é o Deus Criador a quem Jesus se dirigiu como $A b b a$, Pai. O Deus dos pobres, dos pecadores e marginalizados. O Deus que - segundo deixa entrever a indagação de Jó: "De que seio saiu o gelo? Quem deu à luz a geada do céu?" (Jó 38,29) - ama com amor de mãe, a Mãe de todas as criaturas que, agindo livremente, derrama a sua bondade sobre todas as coisas que brotam do trabalho de suas mãos ${ }^{15}$. A fecunda vida do Pai, comunicada eter-

\footnotetext{
${ }^{11}$ Ibid., p. 106.

${ }^{12}$ EDWARDS, D. Ecological Significance of God-language". Theological Studies, 4 (1999), p. 721.

${ }^{13}$ FRANÇA MIRANDA, M., "Para uma teologia do imperativo ecológico". Atualidade Teológica 16 (2004), p.55.

${ }^{14}$ EDWARDS, D. Jesus, The Wisdom of God, op. cit.,p. 120.

${ }^{15}$ Santo Irineu, aproveitando-se de uma metáfora rabínica, usa a metáfora das duas mãos para o ato criador: desde antes da criação, estão o Filho e o Espírito como duas mãos do Pai no
} 
namente ao Verbo, na força do Espírito, "explode" na pluralidade maravilhosa do mundo criado, na exuberância de suas criaturas ${ }^{16}$. Impressiona a atualidade da observação de Santo Tomás sobre a diversidade na criação:

\begin{abstract}
A distinção entre as coisas, assim como a sua multiplicidade, provém da intenção do agente primeiro, que é Deus. Com efeito, Deus produziu as coisas no ser para comunicar sua bondade às criaturas, bondade que elas devem representar. Como uma única criatura não seria capaz de representá-la suficientemente, Ele produziu criaturas múltiplas e diversas, a fim de que o que falta a uma para representar a bondade divina seja suprido por outra. Assim, a bondade que está em Deus de modo absoluto e uniforme está nas criaturas de forma múltipla e distinta. Conseqüentemente, o universo inteiro participa da bondade divina e a representa mais perfeitamente que uma criatura, qualquer que seja ela ${ }^{17}$.
\end{abstract}

Criada por Cristo e em vista de Cristo, a criação recebe vida e dinamismo pela ação do Espírito. É o Espírito de Deus - "o vivificador"- que sustenta todas as coisas e renova a face da terra (S1 104,30). O sopro do Espírito na criação conecta todas as coisas criadas em Deus, constituindo um centro vital cujo dinamismo dá unidade e coesão à multiforme comunidade das criaturas ${ }^{18}$. Dito de outro modo, "o Espírito é o ambiente divino em que todas as criaturas comungam umas com as outras, é elo e laço, união da biodiversidade do universo" 19 .

Toda a criação é perpassada pelo Espírito e é uma realidade cunhada pelo Espírito. Do ponto de vista ecológico essa afirmação tem grande relevância. Para J. Moltmann é necessário reafirmar a presença do Espírito que permeia e vivifica o mundo - o Espírito cósmico - que foi suprimida pela cosmovisão mecanicista dos tempos modernos. ${ }^{20}$ Surge, em decorrência dessa cosmovisão, o símbolo da "máquina-mundo" que substituiu o símbolo mais antigo do "mundo como organismo". Ora, esse tipo de concepção favoreceu o controle e a dominação da natureza pelo homem que pensa que age à

trabalho da criação. Cf. SUSIN, L.C. A Criação de Deus, S. Paulo: Siquem Ediciones e Paulinas, 2003, p. 38.

${ }^{16}$ EDWARDS, D. Ecological Significance of God-language, op. cit.,p. 721.

${ }^{17}$ Suma Teológica II, q. 47, a.1. São Paulo: Edições Loyola, 2002, p. 78.

${ }^{18}$ EDWARDS, D. Jesus, The Wisdom of God, op. cit.,, p. 119.

${ }^{19}$ SUSIN, L. C. A criação de Deus, op., cit.,.p. 38.

${ }^{20}$ MOLTMANN, J., Deus na Criação. Doutrina Ecológica da Criação. Petrópolis: Vozes, 1993, p. 150-157. 
semelhança do Criador, do seu Deus que "não rege tudo como a alma do mundo, mas como um senhor sobre o universo" 21 . Assim, quando se acentua a transcendência de Deus como senhor e dominador, diminuindo ou mesmo esquecendo a sua imanência como Espírito no mundo, então o que surge é uma concepção de natureza a-espiritual e ateísta, uma imagem de mundo desencantado, sem alma e sem vida. Tem razão, pois, Moltmann ao sublinhar reiteradamente a importância do Espírito numa doutrina ecológica da criação. "Sem uma doutrina pneumatológica da criação não existe uma doutrina cristã da criação; sem levar em conta a existência do Espírito criador no mundo não pode haver uma comunhão pacífica entre o ser humano e natureza"22.

Outra característica da criação, ao lado da pluralidade das formas viventes, é o caráter dinâmico e progressivo no interior do próprio mundo criado, uma capacidade interna de invenção, um movimento que conduz a novas possibilidades. Numa palavra, uma criação inacabada, ainda em contínuo processo criativo. Para Moltmann, isso se deve ao dinamismo de autotranscendência que preenche toda a comunidade da criação graças à ação do Espírito cósmico ao agir continuamente na natureza através das seguintes formas $^{23}$ : a) como princípio da criatividade: possibilita o surgimento de novos organismos materiais e vivos; é o princípio da evolução; b) como princípio holístico: cria interrelações, vida em cooperação e comunhão. Ao perpassar todo o mundo, possibilita que cada unidade seja uma parte de um todo e cada parte limitada como uma representação do ilimitado. É o Espírito que une a individualização das criaturas na comunhão de toda a criação. c) como princípio da individualização: dá a identidade de cada indivíduo, de modo que neles auto-afirmação e integração, autopreservação e autotranscendência, não são dados opostos e excludentes, mas são os dois lados do processo de evolução da vida, os quais se completam mutuamente; d) como princípio da intencionalidade: atuando em todos os sistemas da matéria e da vida, o Espírito suscita criaturas abertas, orientadas pelas suas possibilidades, cada uma a seu modo, em direção a um futuro comum.

Assim, para J. Moltmann, "a comunidade da criação", onde todas as coisas coexistem, é também a "comunidade do Espírito" 24 , uma vez que todas as criaturas são partes da mesma comunhão da criação, criação per-

\footnotetext{
${ }^{21}$ Afirmação de Isaac Newton, citado por MOLTMANN, J.; Ibid., p. 150.

${ }^{22}$ Ibid., p. 151.

${ }^{23}$ Ibid., p. 152-153.

24 "The community of creation, in which all created things exist with one another, for one another and in one another, is also the fellowship of the Holy Spirit", citado por. EDWARDS, D., Jesus the Wisdom of God, p.119.
} 
passada pelo Espírito e entendida como uma tessitura dinâmica de eventos relacionados.

Uma vez mais é sublinhada a conexão entre a imanência de Deus no mundo com a sua transcendência do mundo, através da presença do Espírito criador que faz morada no universo. É o Espírito que, ao mesmo tempo, diferencia e interliga, conduzindo as criaturas para além de sua comunhão, pois, se o Espírito cósmico habita todo o mundo, "tudo deve ser entendido como um sistema aberto, para Deus e o seu futuro"25.

Aqui faz-se necessária uma observação que diz respeito ao risco de panteísmo em que essa compreensão do Espírito - que habita toda a criação - poderia incorrer. É sabido que uma visão panteísta da natureza tem sido um argumento usado por muitos na luta contra a destruição ambiental. Não estaria essa compreensão trinitária da criação no Espírito se confundindo com alguma forma de panteísmo?

Sem receios, tendo a exposição de J. Moltmann como apoio ${ }^{26}$, podemos responder negativamente a essa objeção. Não há aqui uma confusão e identificação das criaturas com o criador (tudo é Deus), e sim, uma afirmação de que Deus está presente em suas criaturas (Deus está em tudo) e todas as coisas estão voltadas para Ele pelo dinamismo do Espírito que habita o mundo. Em vez de panteísmo, podemos falar corretamente em um panenteísmo. Mais ainda. Ao se compreender o mundo como um sistema de autotranscendência - na força criadora do Espírito - tudo deve ser entendido como um sistema aberto para Deus (Deus é a origem de novas possibilidades) e Deus como um ser aberto para o mundo (envolve o mundo com as possibilidades do seu ser). Outra vez, reitera-se a relação entre imanência de Deus e a sua absoluta transcendência do mundo.

Com esse enfoque pneumatológico, podemos olhar a natureza como o resultado da ação divina que quis algo distinto, novo e diferente; o Criador quis um mundo portador de autonomia e de invenção. Ora, essa compreensão também poderia ser acusada de insinuar uma forma autônoma e independente de surgimento do mundo ou de expressar uma criação panteísta pela qual a matéria que se auto-organiza também torna-se autocriadora (a natureza que vira natureza, segundo a visão de Spinoza). No entanto, a compreensão bíblico-cristã é muito clara sobre o princípio exclusivo e absoluto Deus - do qual procede o mundo. O mundo não é autocriador nem é uma emanação divina. A narração de Gn 1 inicia a criação do céu e da terra por Deus indicando que "o Espírito do Senhor pairava sobre as águas". O Ruah, o Espírito Divino, pronuncia o primeiro fiat e surge a luz, que vai iluminar

\footnotetext{
${ }^{25}$ MOLTMANN, J. Deus na Criação, p. 157.

${ }^{26}$ Ibid., p. 155-156; 305-306.
} 
todo o resto da criação. Como nos lembra J. Moltmann, "o Espírito é a força criadora e a presença de Deus na sua criação. Toda a criação é uma realidade cunhada pelo Espírito"27. O Deus que continua presente e atuante na natureza e em cada parte dela é o mesmo Espírito criador, o Deus com suas energias não criadas e criadoras. Criado por Deus e existindo em Deus, todo o cosmo movimenta-se e desenvolve-se nas energias e nas forças do Espírito divino. É essa a compreensão de mundo - a maneira pneumatológica de ver a natureza - que emerge da doutrina trinitária da criação ${ }^{28}$.

A tradição do antigo Oriente guardou as seguintes palavras que, poeticamente, expressam a onipresença do Espírito em toda criação: "O Espírito dorme na pedra, sonha na flor, acorda no animal e sabe que está acordado no ser humano" 29 . É o Espírito, enfim, que direciona todas as coisas para o seu futuro comum, a força da nova criação já atuando no mundo presente, fazendo com que todas as criaturas sejam transformadas em Cristo e participem da própria vida de Deus. O texto de Paulo (Rm 8,19-23) quer mostrar essa presença atuante do Espírito nas criaturas, pois,

a criação geme e espera com impaciência porque o dinamismo do Espírito atua também nela. Este dinamismo não sendo respeitado pelo ser humano, devido ao pecado, tornou-se também escravo da corrupção. Não haveria corrupção se não houvesse o dinamismo do Espírito. Como contexto vital do ser humano, obediente ao Espírito, seguidor de Cristo e sintonizado com o desígnio do Pai, ela também poderá participar da 'glória dos filhos de Deus ${ }^{30}$.

Deste modo o universo inteiro é compreendido como obra da Trindade. A Fonte de Plenitude é a Origem sem origem, de onde emana o Ser de todas as criaturas. Jesus é a Sabedoria divina, o Filho eternamente amado pelo Pai em vista de quem todas as coisas são criadas e por quem toda a criação assume uma relação filial com o Criador. O Espírito é a presença divina - "compenetrando e vivificando o mundo por dentro"31, renovando todas as coisas no continuado processo da criação -, é o Amor que une todas as criaturas levando-as a desabrochar e amadurecer na plenitude da Nova

\footnotetext{
${ }^{27}$ MOLTMANN, J. Deus na Criação, p. 151.

${ }^{28}$ Ibid., p. 305.

${ }^{29}$ Cf. BOFF, L. Ecologia: grito da terra, grito dos pobres. Rio de Janeiro: Sextante, 2004, p. 230.

${ }^{30}$ FRANÇA MIRANDA, M., op. cit., p. 58.

${ }^{31}$ JOÃO PAULO II, Dominum et Vivificantem, n. 54. São Paulo, Edições Paulinas, 1986.
} 
Criação ${ }^{32}$. Em suma, o Deus trino da criação é "o Deus-Comunhão-relação, totalmente Outro (transcendência) e totalmente próximo (imanência), numa relação de mútua inclusão-integração, de tal maneira que o senhorio de Deus não exclui, antes inclui, a íntima comunhão com as criaturas e vice-versa",33. Dito de outro modo, o mundo em que vivemos, fruto da Trindade, é a tessitura dinâmica de eventos relacionados - a comunidade da criação - onde todas as coisas coexistem. Deus quis um mundo como a terra do plural e da fecundidade. A natureza é o lugar da diferença e da biodiversidade. É o espaço da coexistência.

\section{O ambiente entendido como espaço geográfico}

Falar de coexistência significa que, na base da compreensão bíblicocristã da criação, encontra-se uma perspectiva que acentua o aspecto relacional e a dinâmica de integração-inclusão das criaturas. Essa leitura, contudo, pode dar a impressão de que o mundo tal qual vivemos seja um espaço harmonioso onde a alteridade e diferença são afirmadas sem ausência de conflitos. Não é bem assim. Sabemos que, em diferentes níveis, a começar do biológico, cujo equilíbrio sistêmico dos ecossistemas supõe o confronto natural das espécies, há uma polarização latente de posicionamentos e interesses a qual resulta na formação de um espaço conflituoso. Uma expressão forte desse conflito se dá no modo como os seres humanos se apropriam da criação, seja na relação desarmônica com a natureza (polaridade antropocentrismo x biocentrismo), seja nas relações desiguais entre si (conflito de poder). Em ambos os casos, o que está em jogo é a alteridade e o direito do outro à existência.

É dentro desse quadro de conflito de interesses que situa-se a questão ambiental e a temática da sustentabilidade. Chegamos, assim, ao segundo ponto da nossa exposição. Aqui, queremos ressaltar que a visão teológica da criação se enriquece com a contribuição de outros campos do saber, entre eles, o conceito de espaço geográfico segundo o qual a noção de ambiente, mesmo considerada na sua base biofísica, não pode ser separada de sua dimensão social.

Nas palavras de Bertha Becker:

A tendência dominante é uma tendência naturalizada do ambiente, que enfatiza o meio físico. Repensar o concei-

\footnotetext{
${ }^{32}$ EDWARDS, D. Jesus, The Wisdom, op. cit. p. 122.

${ }^{33}$ RUBIO, A. G. Unidade na Pluralidade. O ser humano à luz da fé e da revelação cristãs. S. Paulo: Paulus, 2001, p. 559.
} 
to implica desenvolver uma abordagem integrativa capaz de superar essa noção exclusivamente biogeográfica do ambiente - que confunde com ecossistemas naturais - e evitar o erro de dissociar os seus constituintes 'físicos e 'sociais', porque o ambiente é o resultado da interação da lógica da natureza e da lógica da sociedade. Tratase, portanto, de uma concepção social do ambiente ${ }^{34}$.

Essa concepção social do ambiente justifica-se, segundo Milton Santos, porque "a natureza é continente e conteúdo do homem, incluindo os objetos, as ações, as crenças, os desejos, a realidade esmagadora e as perspectivas $^{35}$. Interessante notar que não lidamos aqui com um conceito meramente abstrato, vazio de conteúdo e de sujeitos. Trata-se, antes, do espaço do cotidiano, espaço vivido, das lutas diárias, do acontecer, das relações (das pessoas entre si e com seu entorno natural).

Tal espaço é entendido como uma realidade mista, como um híbrido, isto é, um conjunto inseparável de sistemas de objetos e sistemas de ações. As coisas encontradas na natureza, quando utilizadas pelos seres humanos, tornam-se objetos. "No começo era a natureza selvagem, formada por objetos naturais que, ao longo da história, vão sendo substituídos por objetos fabricados", afirma Milton Santos ${ }^{36}$. De modo que a configuração espacial vai se dando ao longo da história pela herança natural modificada, recriada e ressignificada pela ação humana que se objetivou nas formas materiais.

Qual o significado ecológico dessa concepção espacial? Vejamos um exemplo: uma população tradicional de pescadores é um componente que, junto com outros fatores bióticos e abióticos, forma um ecossistema no qual as interrelações asseguram o equilíbrio e a sucessão dos ciclos vitais. Quando se constrói uma ponte ou um dique para controlar o fluxo das águas, a materialidade do espaço será modificada com a introdução desse novo objeto. Toda a vida do ecossistema será afetada pela construção do objeto (a ponte, o dique, etc.).

Note-se ainda que os objetos são criados por intencionalidades específicas, em geral, com caráter mercantil e representando interesses de grupos

\footnotetext{
${ }^{34}$ BECKER, Bertha e GOMES, Paulo César da Costa. "Meio Ambiente: matriz do pensamento geográfico". In: VIEIRA, Paulo Freire e MAIMON, Dália (orgs). As Ciências Sociais e a Questão Ambiental, rumo à interdisciplinaridade. Rio de Janeiro e Belém: APED E UFPA, 1993, p. 172.

35 SANTOS, M. Técnica, Espaço, Tempo. Globalização e meio técnico-científicoinformacional. São Paulo: Editora Hucitec, 1994, p. 15.

${ }^{36}$ SANTOS, M. A Natureza do Espaço. Técnica e Tempo, Razão e Emoção. São Paulo: Edusp, 2006, p. 63.
} 
economicamente poderosos. O espaço, portanto, não é um dado neutro, pois os objetos obedecem a quem tem poder para comandar as ações. Com frequência os objetos atendem a interesses de fora, seguindo a intencionalidade de agentes sociais dominantes que não levam em conta a particularidade e especificidades locais (características de cada ecossistema, as culturas locais, a aptidão econômica do lugar, etc.)

Ademais, o espaço enquanto compreendido como território é uma base material socialmente construída através de processos de apropriação/dominação, tornando-se uma condição para manifestações das identidades locais e das relações sociais, já que o controle desse espaço é fator decisivo para o exercício do poder ${ }^{37}$. O espaço feito território, portanto, não é simplesmente uma categoria político-administrativa. Ele existe enquanto realidade primeira para ser praticado e produzido historicamente, constituindo-se o espaço de exercício do poder político. Ora, se é produzido historicamente, ele traduz as especificidades das opções socioculturais e econômicas de cada povo. A título de exemplo, façamos a seguinte indagação: na configuração espacial local de algumas áreas do litoral nordestino, que efeito está tendo a expansão da carcinocultura? Essa atividade produtiva atende aos interesses das populações nativas? O que vemos, infelizmente, é o catador de caranguejo perdendo o seu território para o produtor de camarão que ali se instala, destruindo os manguezais com os reservatórios artificialmente construídos (objetos).

A concepção geográfico-espacial, portanto, aponta para um dinamismo na relação espaço-sociedade - se quisermos, na relação ser humano/ambiente - movido por uma lógica de modelos dominantes que vai se impondo nos diferentes níveis de organização social. Como resultado, o "espaço banal" - como lembra Milton Santos - que seria o espaço de todos num entrelaçamento plural de organizações e ações, termina sendo o espaço de uns poucos, pois "só os atores hegemônicos se servem de todas as redes e utilizam todos os territórios ${ }^{38 "}$. Assim, o modelo dominante vai impondo-se nos diferentes níveis organizacionais, gerando espacialidades ou desenvolvimentos desiguais ${ }^{39}$.

O conceito de espaço feito território nos ajuda a ver que a crise ecológica de nossos dias revela-se como uma crise socioambiental. Vivemos hoje um processo de "unificação da natureza" ou tecnificação do espaço como

\footnotetext{
${ }^{37}$ SOUZA, Marcelo José Lopes de. "Algumas notas sobre a importância do espaço para o desenvolvimento social”. Território, Rio de Janeiro, n. 3, 1997, p.24-29.

38 SANTOS, M. Técnica, Espaço, Tempo. Globalização e meio técnico-científicoinformacional. São Paulo: Editora Hucitec, 1994, p. 53.

${ }^{39}$ HARVEY, D. Espaços de Esperança. São Paulo: Ed. Loyola, 2004.
} 
conseqüência da atuação desses dois fatores - os objetos técnicos e atores sociais hegemônicos - que são os principais responsáveis pelo processo de globalização, processo que não leva em conta a alteridade, a diferença e a cultura local ${ }^{40}$. Nesse contexto, cresce, em importância, o conhecimento e a valorização do lugar enquanto locus da união dos grupos humanos pela cooperação na diferença. A perversidade da globalização é enfrentada no lugar.

\begin{abstract}
A dimensão fragmentada é a tribo - união de homens por suas semelhanças - e o lugar - união dos homens pela cooperação na diferença. A grande revolta se dá através do espaço, do lugar, ali onde a tribo descobre que não é isolada, nem pode estar só ${ }^{41}$.
\end{abstract}

É o local, sem esquecer a necessária conexão com o global, que permite a união, como o espaço da "extensão do acontecer solidário". É no lugar, a base da vida em comum, que se pode rever a lógica do mundo. Ele é, segundo M. A. de Souza, "o ponto da construção da resistência" enquanto é o espaço do cotidiano, onde a vida acontece concretamente ${ }^{42}$.

A categoria espaço/território, enfim, possibilita pensar o espaço como aquela "teia de relações", da multiplicidade em que os indivíduos estão interligados, da diferenciação que ajusta-se na complementaridade dialética do eu e do outro. É a arena dinâmica da vida, em que tudo está relacionado com tudo - do local ao global - num processo sistêmico e holístico que, contudo, respeita a particularidade e a subjetividade de cada componente, salvaguardando a identidade de cada grupo e o direito de construir a sua própria história. Deixando fluir a dinâmica da integração-inclusão, o espaço assim considerado permite superar as variadas dicotomias (sujeito-objeto, natureza-ser humano, adiantado-atrasado etc.) - relação desigual em que um dos pólos fica esquecido ou dominado pelo outro - e dá condições para se pensar em uma existência relacional e harmoniosa.

\title{
3. Uma visão inclusiva/integradora de sustentabilidade
}

Chegamos ao terceiro ponto de nossa reflexão. O conceito geográfico de espaço, como vimos, quando relacionado à questão ecológica, implica levar a discussão sobre sustentabilidade ambiental para o campo das relações

\footnotetext{
${ }^{40}$ SANTOS, M. A Natureza do Espaço, p. 253.

${ }^{41}$ Ibid. p. 36.

42 SOUZA, M.A.A. “A geopolítica do desenvolvimento sustentável: panorama mundial. O planeta e as metáforas”. SOTER (org.), São Paulo: Paulinas, 2008, p. 27.
} 
sociais. "A sustentabilidade remete a relações entre a sociedade e a base material de sua reprodução", adverte Acserald ${ }^{43}$. Isso significa que a questão do desenvolvimento sustentável, além do meio ambiente, envolve também o tema das formas sociais de apropriação e uso do próprio ambiente. Trata-se, na verdade, de uma "luta social", já que existe um conflito entre diferentes modos de apropriação e uso da base material das sociedades. Portanto, devese buscar uma nova maneira, uma nova dinâmica de uso da base material do desenvolvimento, o que implica, entre outras coisas, legitimar atores e considerar a diversidade, de modo que "sejam afirmadas diferentes formas culturais de relação com a base material das sociedades" $"$. Há, pois, a necessidade de se pensar um outro desenvolvimento - como lembra Sachs - que seja endógeno, voltado para os atores e culturas locais (e não como transposição mimética de modelos alienígenas), autossuficiente (em vez de dependente), orientado para as necessidades (em lugar de direcionado pelo mercado), em harmonia com a natureza e aberto às mudanças das estruturas sociais injustas ${ }^{45}$.

Para tanto, urge uma "racionalidade ambiental", como propõe Enrique Leff, com a qual se estabeleçam princípios éticos e teóricos, cujos valores neles embutidos possam orientar a busca de modelos autênticos de desenvolvimento $^{46}$. Segundo Silva, considerando a realidade de um país como o Brasil, esses princípios poderiam ser traduzidos da seguinte maneira: equidade e participação social; diversidade sociocultural e ecossistêmica; autonomia local, autossuficiência e estabilidade; integração do ser humano ao meio ambiente; fortalecimento das comunidades rurais e permanência na terra; articulação entre uma ciência moderna, mais holística e integradora, e o saber tradicional ${ }^{47}$.

Dentro dessa racionalidade ambiental, destaca-se a valorização do lugar, como a base da vida em comum que permite "a união dos homens pela cooperação na diferença" ${ }^{48}$. Nesse sentido, é importante um olhar valorativo sobre as formas de convivência com a natureza, desenvolvidas secu-

43 ACSERALD, H. "Sustentabilidade e Desenvolvimento: modelos, processos e relações". Rio de Janeiro: Projeto Brasil Sustentável e Democrático: FASE, 2a edição, 2003, p. 37.

${ }^{44}$ Ibid., p. 41.

45 SACHS, I. Caminhos para o desenvolvimento sustentável. Rio de Janeiro: Garamond, $4^{\mathrm{a}}$ edição, 2002, p . 53-54.

${ }^{46}$ LEFF, E. Saber Ambiental. Sustentabilidade, Racionalidade, Complexidade, Poder. Petrópolis: Vozes, 2004, p. 138-139.

${ }^{47}$ SILVA, C. E. M. "Democracia e sustentabilidade na agricultura: subsídios para a construção de um novo modelo de desenvolvimento rural”. In: Rio de Janeiro: Projeto Brasil Sustentável e Democrático. FASE, 2001, p. 45.

${ }^{48}$ SANTOS, M. Técnica, Espaço, Tempo, op. cit., p. 36. 
larmente pelas populações tradicionais, ou seja, buscar nesses lugares as especificidades etnoculturais, econômicas e ecológicas e deixar que elas indiquem possibilidades de modelos democráticos de desenvolvimento e formas verdadeiramente sustentáveis de apropriação dos territórios ${ }^{49}$. A busca de um desenvolvimento sustentável, portanto, deve ter como base a sustentabilidade dos lugares. Com efeito, segundo Silva, trata-se "mais de envolvimento local do que de des-envolvimento de fora para dentro"

Ganha, pois, em importância, o acento nas comunidades e a necessidade de apoio nas suas lutas para que seja respeitado o princípio de autonomia e autodeterminação, sem esquecer do necessário esforço de articulação com o global. Essa foi a estratégia que esteve na base, por exemplo, do modelo buscado por Chico Mendes e pelo movimento dos seringueiros no Acre $^{51}$. Tal modelo enquadra-se nos parâmetros já apresentados por Sachs na sua proposta de um ecodesenvolvimento: "O ecodesenvolvimento requer o planejamento local e participativo, no nível micro, das autoridades locais, comunidades e associações de cidadãos envolvidos na proteção da área"52. Importa ainda destacar - no âmbito do "lugar" enquanto "extensão do acontecer solidário", como o chamava Milton Santos - o importante papel da mulher nas estratégias de desenvolvimento de sistemas sustentáveis de produção, buscando a articulação entre ecologia e agricultura familiar, postos em práticas em muitas experiências no interior rural do Brasil ${ }^{53}$. É importante valorizar esses espaços onde as populações tradicionais - com ênfase na atuação da mulher camponesa - mantém práticas agroecológicas, contrárias ao modelo simplificador da agricultura moderna/mercantil, que favorece, entre outras coisas, a manutenção tão necessária da biodiversidade. Esse tipo de produção familiar, como Silva adverte, deveria receber apoio e incentivo das políticas públicas e dos sistemas de ensino/pesquisa/extensão ${ }^{54}$.

Quando fala-se hoje na necessidade de preservar a diversidade da natureza, esse princípio deve ser entendido segundo uma perspectiva inclusiva ou integradora. Se o respeito à biodiversidade é visto como um imperativo ético para o desenvolvimento sustentável, como nota $\mathrm{Sachs}^{55}$, uma preocu-

\footnotetext{
${ }^{49}$ Sobre a importância das agriculturas camponesas e indígenas, e os seus valores culturais, sociais e econômicos, na busca de modelos de desenvolvimento sustentável, cf. MACHADO,

A. T. "Biodiversidade e Agroecologia". In: BOEF, W. S., Biodiversidade e agricultores: fortalecendo o manejo comunitário, Porto Alegre: L\&PM editores, 2007, p. 40-45.

${ }^{50}$ SILVA, C. E. M., op. cit., p. 46.

${ }^{51}$ SILVA, C. E. M., op. cit., p. 47.

${ }^{52}$ SACHS, I. Caminhos para o desenvolvimento sustentável, op. cit., p. 73.

${ }^{53}$ SILVA, C. E. M., op. cit., p. 97-100.

${ }^{54}$ Ibid., p. 100.

${ }^{55}$ SACHS, I. Caminhos para o desenvolvimento sustentável, op. cit., p. 67.
} 
pação igualmente ética é a manutenção da diversidade das culturas e dos povos, particularmente das populações tradicionais, as principais guardiãs da biodiversidade $^{56}$. Em outras palavras, urge preservar a sociobiodiversidade: quanto mais pluricultural é um povo, mais chance existe para uma convivência sustentável com o mundo natural, porque "as várias culturas se tornam

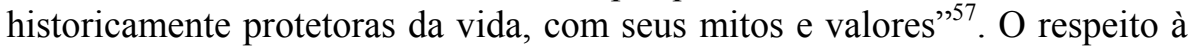
biodiversidade ecossistêmica alinha-se com o respeito à pluralidade de culturas, constituindo a base para a sustentabilidade, a igualdade e a justiça ${ }^{58}$. O desenvolvimento é algo a ser pensado no plural e no respeito à alteridade. Tinha razão, pois, Milton Santos quando questionava a possibilidade de um "crescimento no singular"

\section{Conclusão}

O que vimos sobre a visão geográfico-espacial de ambiente e a perspectiva integradora/inclusiva de sustentabilidade não deveria estar distante da reflexão teológica. Retomamos aqui o ponto por onde iniciamos e com o qual queremos concluir este artigo. Com efeito, o tema da pluralidade e o respeito à diferença aparece na teologia da criação como uma das características do mundo querido por Deus. O espaço para a alteridade encontra a sua fundamentação primeira na Trindade: um Deus em si mesmo diferente (dinamismo divino trinitário), deixa no mundo criado as marcas do dinamismo e da diferença. Deus quis um mundo como a terra do plural e da fecundidade. A natureza, com toda a exuberância de sua sociobiodiversidade, à imagem de Deus, é o lugar da diferença e da pluralidade.

Infelizmente, a hegemonia de um modelo de desenvolvimento (ocidental/capitalista) sufoca o princípio da diferenciação que as "marcas" da Trindade imprimem nas culturas. $\mathrm{O}$ olhar contemplativo sobre a criação deveria convidar-nos a uma mudança radical de atitude. Aqui, teologia e ecologia dão-se as mãos no apelo que nos fazem a uma verdadeira metanoia na direção da salvaguarda da diversidade socioambiental.

\footnotetext{
${ }^{56}$ Como nota Machado: “A biodiversidade trabalhada pelas populações tradicionais requer um profundo entendimento de seu ecossistema. Essas formas milenares de manejo serviram como base para as diferentes formas de agricultura ecológica existentes hoje". MACHADO, A. T. "Biodiversidade e Agroecologia", op. cit., p. 41.

${ }^{57}$ OLIVEIRA, J. BORGES, W. Ética de Gaia, op. cit., p. 191.

${ }^{58}$ SACHS, I. Caminhos para o desenvolvimento sustentável, op. cit., p. 67.

${ }^{59}$ SANTOS, M. Técnica, Espaço, Tempo, p. 58.
} 


\section{Referências Bibliográficas}

ACSELRAD, H. Sustentabilidade e Desenvolvimento: modelos, processos e relações. Rio de Janeiro: Projeto Brasil Sustentável e Democrático. FASE, $2^{\mathrm{a}}$ edição, 2003.

BECKER, B e GOMES, P. C. da Costa. Meio Ambiente: matriz do pensamento geográfico. In: VIEIRA, P. F. E MAIMON, D. (orgs). As Ciências Sociais e a Questão Ambiental, rumo à interdisciplinaridade. Rio de Janeiro e Belém: APED e UFPA, p. 147-174.

BOFF, L. Ecología: grito da terra, grito dos pobres. Rio de Janeiro: Sextante, 2004.

EDWARDS, D. Jesus, The Wisdom of God. An Ecological Theology. New York: Orbis Books, 1995.

, The Ecological Significance of God Language. Theological Studies, 4 (1999), p. 708-722.

FRANÇA MIRANDA, M. Para uma teologia do imperativo ecológico. Atualidade Teológica, 16 (2004), p. 48-60.

GESCHÉ, A. O Cosmo. São Paulo: Paulinas, 2004.

HARVEY, D. Espaços de Esperança. São Paulo: Ed. Loyola, 2004.

JOÃO PAULO II, Dominum et Vivificantem, n. 54. São Paulo, E. Paulinas, 1986.

JUNGES, J. R. Ecologia e Criação - Resposta cristã à crise ambiental. S. Paulo: Edições Loyola, 2001, 103 p.

LACUGNA, C. M. God for Us: The Trinity and Christian Life. San Francisco: HarperSanFrancisco, 1991.

LEFF, E. Saber Ambiental. Sustentabilidade, Racionalidade, Complexidade, Poder. Petrópolis: Vozes, $3^{\text {a }}$ edição, 2004.

MACHADO, A. T. Biodiversidade e Agroecologia. In: BOEF, W. S. de. Biodiversidade e agricultores: fortalecendo o manejo comunitário. Porto Alegre: L\&PM editores, 2007, p. 40-45.

MOLTMANN, J., Deus na Criação. Doutrina Ecológica da Criação, Petrópolis: Vozes, 1993.

NOEMI, J. Mysterium Creationis: Sobre a Possibilidade de uma Aproximação à Realidade como Criação de Deus. In: SUSIN, L.C. (org.). Mysterium Creationis: Um olhar interdisciplinar sobre o Universo. São Paulo, Paulinas, 1999, p. 205-247.

OLIVEIRA, J. e BORGES, W. Ética de Gaia. Ensaios de ética socioambiental. São Paulo: Paulus, 2008.

RUBIO, A. G. Unidade na Pluralidade: O Ser Humano à luz da Fé e da Revelação Cristãs. São Paulo: Paulus, 2001. 
SACHS, I. Caminhos para o desenvolvimento sustentável. Rio de Janeiro: Garamond, $4^{\mathrm{a}}$ edição, 2002.

SANTOS, M. A Natureza do Espaço. Técnica e Tempo, Razão e Emoção. São Paulo: Edusp, $4^{\circ}$ edição, 2006.

, Técnica, Espaço, Tempo. Globalização e meio técnicocientífico-informacional. São Paulo: Editora Hucitec, 1994.

SILVA, C. E. M. Democracia e sustentabilidade na agricultura: subsídios para a construção de um novo modelo de desenvolvimento rural. Rio de Janeiro: Projeto Brasil Sustentável e Democrático, FASE, 2001.

SOUZA, M. A. A. A geopolítica do desenvolvimento sustentável: panorama mundial. O planeta e as metáforas. In: SOTER (org.), Sustentabilidade da Vida e Espiritualidade. São Paulo: Paulinas, 2008, p. 15-37.

SOUZA, M. J. L. de. Algumas notas sobre a importância do espaço para o desenvolvimento social. Território, Rio de Janeiro, n. 3, 1997, p. 1335 .

SUSIN, L. C. A Criação de Deus. São Paulo: Siquem Ediciones e Paulinas, 2003.

\title{
Resumo
}

O presente texto pretende abordar a teologia da criação numa perspectiva ecológica. Para tanto, parte de uma leitura trinitária da criação como fundamento da biodiversidade do mundo criado. Essa leitura se enriquece quando recorremos ao conceito geográfico de espaço, cuja ênfase na dimensão social do ambiente nos faz ver que o cuidado ecológico se alinha com o respeito à pluralidade das culturas. Tal visão integradora/inclusiva do ambiente constitui a base para a sustentabilidade, a igualdade e a justiça social, e converge para uma compreensão teológica segundo a qual a criação, como imagem do Deus Trinitário, pode ser considerada o lugar da diferença e da pluralidade.

Palavras-chave: Leitura Trinitária da Criação, o Conceito Geográfico de Espaço, Sociobiodiversidade, Sustentabilidade Ambiental.

\begin{abstract}
The present text intends to analyze the theology of creation in a perspective based on ecology. In order to do so, it starts from a trinitarian vision of creation as the basis of the created world's biodiversity. This view is enriched with the geographic concept of space, whose emphasis on the social dimen-
\end{abstract}


sion of the environment enables one to conclude that the ecological care aligns itself with the respect towards the plurality of cultures. This integrating/inclusive perspective of the environment composes the grounds for sustainability, equality and social justice, and converges to a theological understanding according to which the creation, as a trinitarian image of God, may be considered a place of difference and plurality.

Keywords: Trinitarian Vision of Creation, the Geographical Concept of Space, Social Biodiversity, Environmental Sustainability.

Lúcio Flávio Ribeiro Cirne

Professor do Curso de Bacharelado em Teologia da UNICAP

Doutor em Teologia pela PUC-Rio

Engenheiro Agrônomo pela UFPb

E-mail: luciosj@yahoo.com

Artigo Recebido em 02/02/2011

Artigo Aprovado em 15/03/2011 